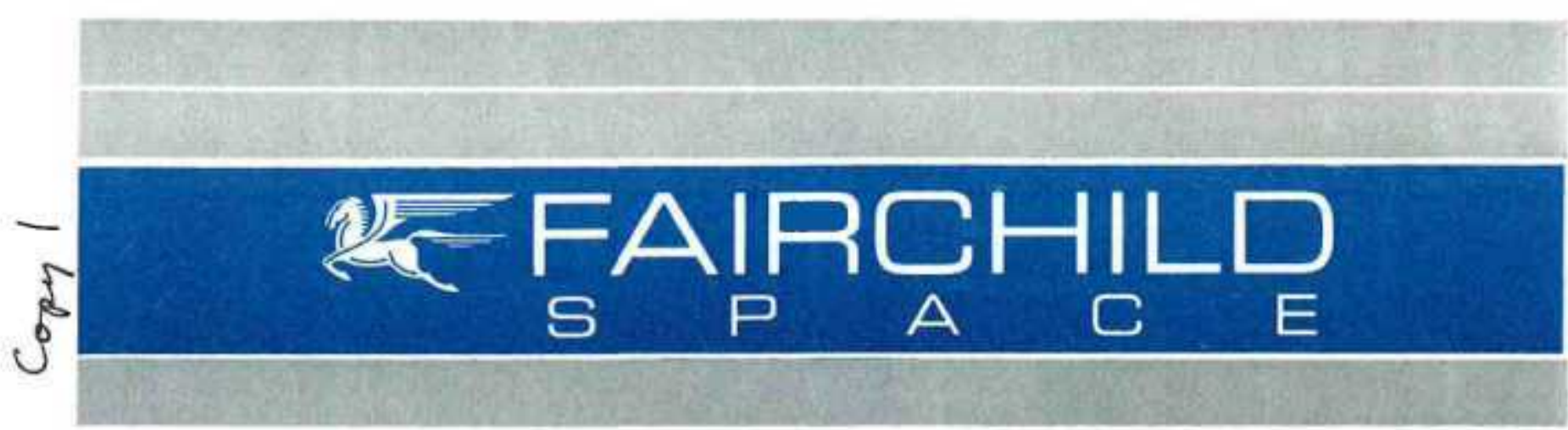

$\sigma$
0
0
0
0
0
0
0

\title{
RADIOISOTOPE STIRLING GENERATOR OPTIONS FOR PLUTO FAST FLYBY MISSION
}

\author{
Alfred Schock \\ Fairchild Space and Defense Corporation \\ 20301 Century Blvd, A-35 \\ Germantown, MD 20874 U.S.A \\ (301) 428-6272
}




\title{
RADIOISOTOPE STIRLING GENERATOR OPTIONS FOR PLUTO FAST FLYBY MISSION
}

\author{
Alfred Schock \\ Fairchild Space and Defense Corporation \\ 20301 Century Blvd., A-35 \\ Germantown, MD 20874 U.S.A \\ (301) 428-6272
}




\title{
RADIOISOTOPE STIRLING GENERATOR OPTIONS FOR PLUTO FAST FLYBY MISSION
}

\author{
Alfred Schock \\ Fairchild Space and Defense Corporation \\ 20301 Century Blvd., A-35 \\ Germantown, MD 20874 U.S.A
}

(301) 428-6272

\begin{abstract}
The preceding paper described conceptual designs and analytical results for five Radioisotope Thermoelectric Generator (RTG) options for the Pluto Fast Flyby (PFF) mission, and the present paper describes three Radioisotope Stirling Generator (RSG) options for the same mission. The RSG options are based on essentially the same radioisotope heat source modules used in previously flown RTGs and on designs and analyses of a 75-watt free-piston Stirling engine produced by Mechanical Technology Incorporated (MTI) for NASA's Lewis Research Center. The integrated system design options presented were generated in a Fairchild Space study sponsored by the Department of Energy's Office of Special Applications, in support of ongoing PFF mission and spacecraft studies that the Jet Propulsion Laboratory (JPL) is conducting for the National Aeronautics and Space Administration (NASA). That study's NASA-directed goal is to reduce the spacecraft mass from its baseline value of $166 \mathrm{~kg}$ to $-110 \mathrm{~kg}$, which implies a mass goal of less than $10 \mathrm{~kg}$ for a power source able to deliver 69 watts(e) at the end of the 9.2-year mission. In general, the Stirling options were found to be lighter than the thermoelectric options described in the preceding paper. But they are less mature, requiring more development, and entailing greater programmatic risk. The Stirling power system mass ranged from $7.3 \mathrm{~kg}$ (well below the $10-\mathrm{kg}$ goal) for a non-redundant system to $11.3 \mathrm{~kg}$ for a redundant system able to maintain full power if one of its two engines fails. In fact, the latter system could deliver as much as $\mathbf{1 1 5}$ watts(e) if desired by the mission planners.
\end{abstract}

\section{INTRODUCTION}

The Pluto Fast Flyby (PFF) mission, its scientific motivation, and the reason for the urgency of an early arrival at Pluto were briefly discussed in the preceding paper. That urgency dictated further mass reduction goals, beyond the drastic reductions already achieved in JPL's 1992 baseline design.

JPL's present goal is to reduce the spacecraft mass from $165 \mathrm{~kg}$ to about $110 \mathrm{~kg}$. In that connection, the JPL study team has set a goal of reducing the mass of the PFF power source by $47 \%$, from $17.8 \mathrm{~kg}$ to $9.5 \mathrm{~kg}$. To meet the baseline power demand with $20 \%$ contingencies and 10\% margin, the power source must be able to deliver 69 watts(e) at the end of 9.2 years.

In support of the JPL study, the Department of Energy had requested Fairchild to explore a number of radioisotope power system options, to assess each option's mass, technical maturity, and programmatic risk. The study results are intended to support informed trade-off decisions by program management. The preceding paper [Schock 1993] presented the results for a total of five thermoelectric options. They ranged in mass from $19.3 \mathrm{~kg}$ to 10.2 $\mathrm{kg}$. Unfortunately, the thermoelectric options that came closest to the stipulated mass goal are the ones that require the greatest development and entail the highest programmatic risk.

Additional studies of possible PFF power systems are under way at Fairchild. These employ radioisotope heat sources with more efficient conversion systems than thermoelectrics. The present paper describes three options employing Stirling engines, specifically free-piston Stirling engines. 


\section{STIRLING ENGINES}

Stirling engines, like other dynamic systems, offer much higher conversion efficiencies than thermoelectric systems. Tripling or quadrupling the efficiency of current RTGs would greatly reduce the cost and mass of the required fuel loading. Unlike other dynamic conversion systems, Stirling engines retain their high efficiencies at very low output powers, which is important for low-power applications like PFF. In addition, in free-piston Stirling engines with built-in linear alternators, reliability and lifetime are enhanced by elimination of seals, solid bearings, lubricants, and external penetrations.
In conducting its Stirling system studies for PFF, Fairchild elected to base its system designs on a freepiston Stirling engine and alternator design furnished by Mechanical Technology Incorporation. MTI has been engaged in the development of various free-piston engines for over 15 years for a number of government agencies. They recently designed, built, and tested such a system for an output of $25 \mathrm{~kW}(\mathrm{e})$ for NASA's Lewis Research Center (LeRC) [Dochat and Dudenhoefer 1993 and Dochat and Dudenhoefer 1994]. The disassembled hardware of that system is depicted in Figure 1.

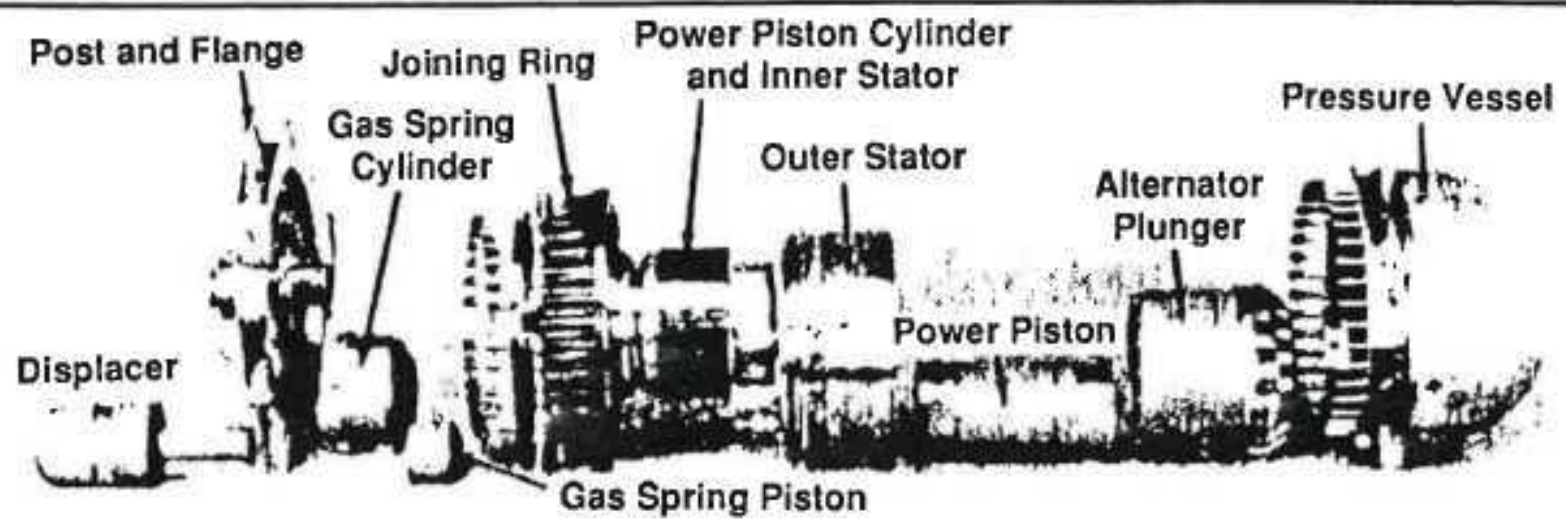

Fig. 1. Stirling Engine.

The assembled system has not yet been subjected to long-term endurance tests, but the tests to date gave results that closely matched MTI's analytical predictions 1.3 kwe per engine half at $22.5 \%$ electrical efriciency). This agreement lends confidence in the analyticat techniques employed in designing the system and in predicting its performance. At the request of LeRC, MTI has used the same techniques to design and analyze much smaller versions of the same engine and alternator in support of Fairchild's PFF power system studies. The results of their design analyses for a 250-watt and a 75-watt engine are summarized in Table 1.

Table 1. Space Stirling Power Converters, Results of MTI Design Analyses.

\begin{tabular}{|ll|c|c|}
\hline & Design Power & $250 \mathrm{~W}$ & $75 \mathrm{~W}$ \\
\hline Operating Parameters & & & \\
Working Fluid & & Helium & Helium \\
Mean Pressure & $(\mathrm{MPa} / \mathrm{psi})$ & $6 / 870$ & $4.4 / 638$ \\
Frequency & $(\mathrm{Hz})$ & 90 & 76 \\
Healer Melal Temperature & $(\mathrm{K})$ & $1040 / 767$ & $1040 / 767$ \\
Cooler Metal Temperalure & $(\mathrm{K})$ & $416 / 143$ & $416 / 143$ \\
Displacer Stroke & $(\mathrm{mm})$ & 5.3 & 5.2 \\
Pislon Stroke & $(\mathrm{mm})$ & 6.4 & 6.4 \\
Displacer-lo-Piston Phase & $\left({ }^{\circ}\right)$ & 67 & 67 \\
Performance & & & \\
Heat Input & $(\mathrm{W})$ & 1000 & 326 \\
Electrical Output Power & $(\mathrm{W})$ & 250 & 75 \\
Engine Indicaled Efliciency & & 0.35 & 0.32 \\
Engine Mechanical Efficiency & & 0.82 & 0.83 \\
Alternalor Elficiency & 0.88 & 0.88 \\
Overalt Efficiency & & 0.25 & 0.23 \\
Mass, Incl. Vibration Absorber (kg) & & 8.75 & 3.75 \\
& & & \\
\hline
\end{tabular}


Figure 2 presents a cross-section view of MTI's 75-watt engine design. That engine and the MTIcomputed performance parameters listed in Table 1 were used as the basis for the Fairchild study.

It is not the intent in this paper to offer a detailed description of the MTI design and its rationale. That must await a separate paper by MTI personnel. The present paper will focus its attention on Fairchild's task of thermally and mechanically integrating the engine with radioisotope heat sources and with suitable heat rejection radiators.

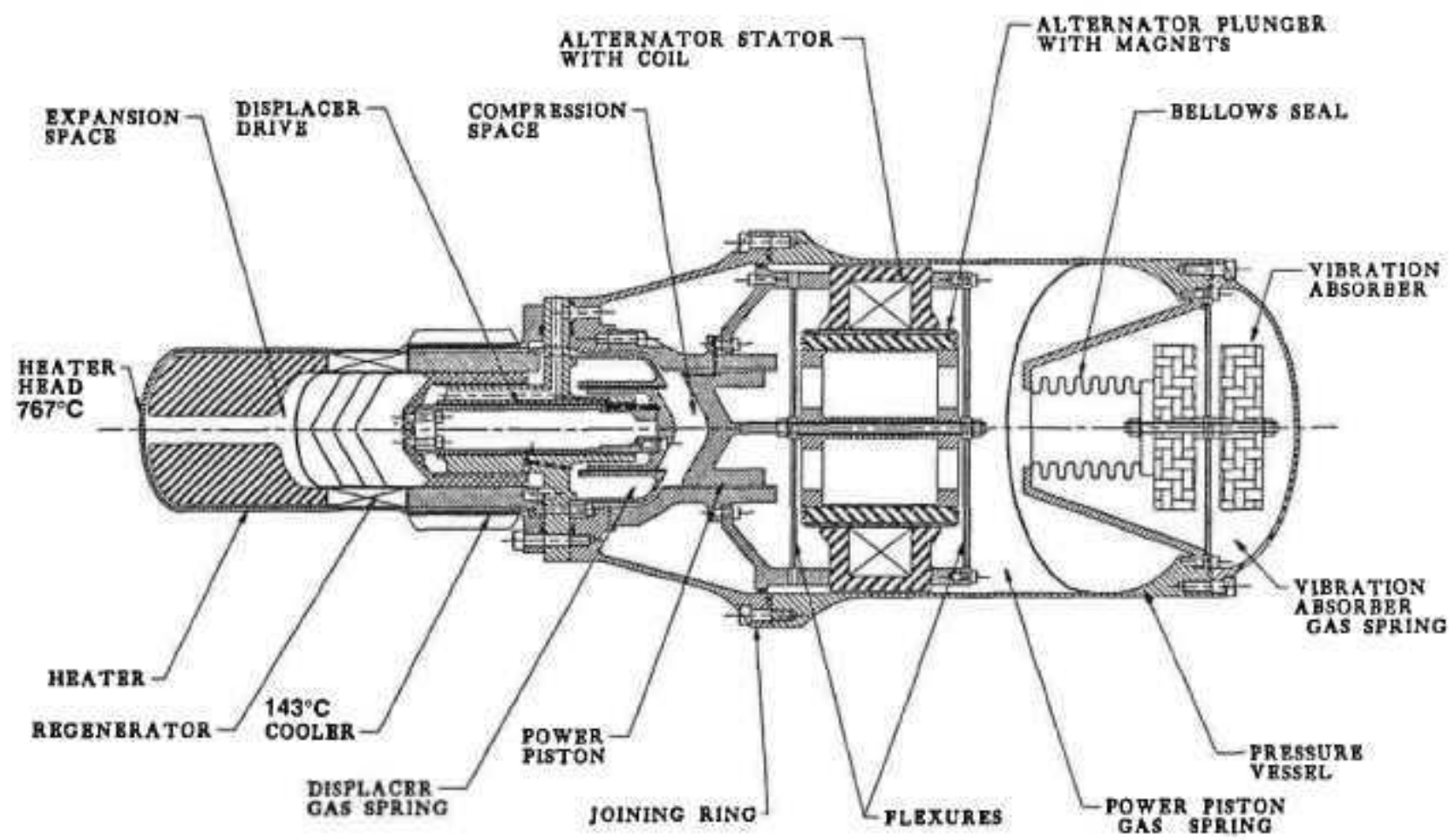

Fig. 2. MTI 75-Watt Stirling Power Converter (Overall Length $=14^{\prime \prime}$ ).

\section{RADIOISOTOPE HE.AT SOURCE}

The study endeavored to employ the same General Purpose Heat Source (GPHS) modules that had bcen safety-qualified and flown on RTGs for the Galileo and Ulysses missions [Schock 1980] and that had also been used as the basis of the PFF RTG design options described in the preceding paper. The GPHS module design is depicted in Figure 3. As seen, its thermal power with maximum fuel loading is 250 watts at beginning of mission (BOM).

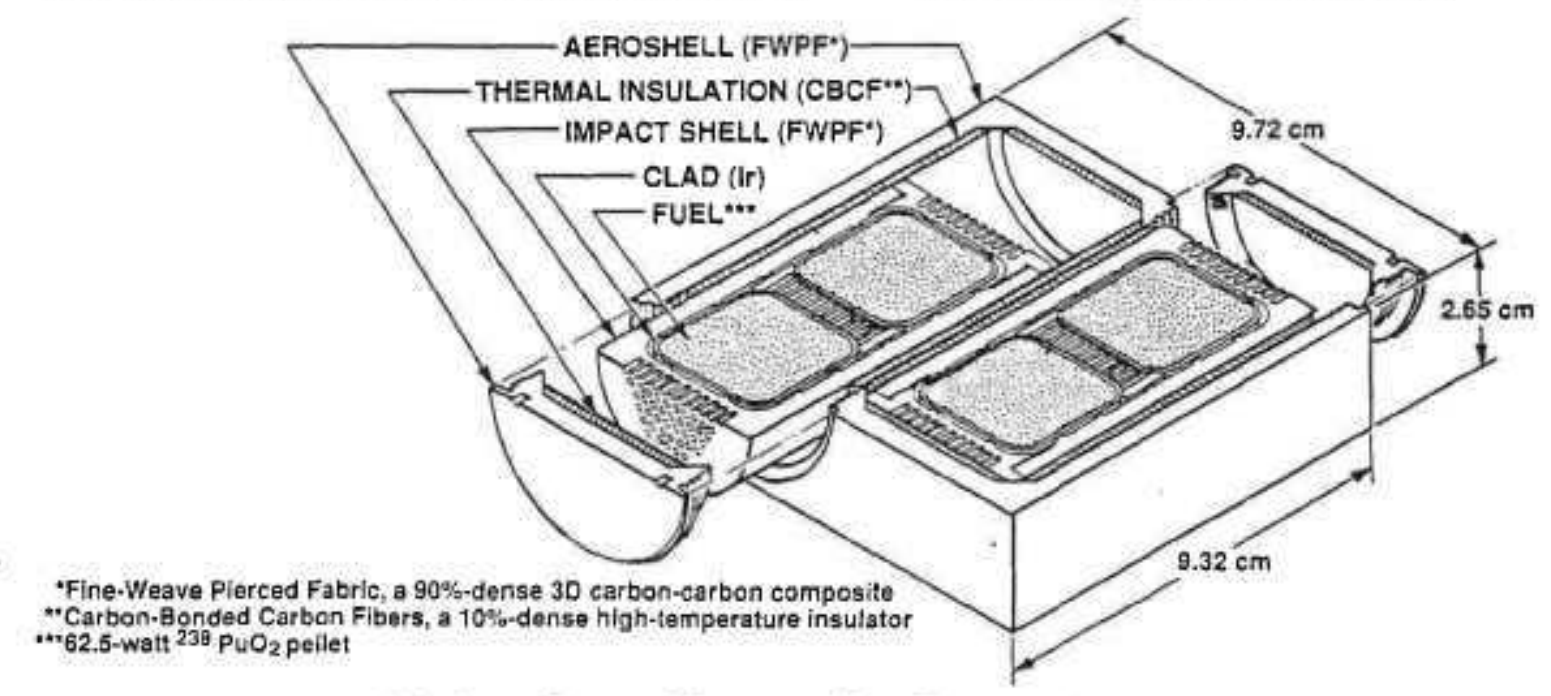

Fig. 3. General-Purpose Heat Source Module (250 Watt) 
As was shown in Table 1, the 75-watt MTI Stirling engine design calls for a heat input rate of 326 watts. Adding allowances for thermal losses and fuel decay during the mission leads to an estimated BOM thermal power requirement of approximately 375 watts which corresponds to 1.5 standard heat source modules. There are three options for dealing with this mismatch:

1) Employ a modified heat source module with six instead of four standard (62.5-watt) fuel capsules.

2) Employ two standard GPHS modules with their thermal power reduced by lowering their fuel loading and/or isotopic enrichment.

3) Employ two standard GPHS modules with full thermal power, and utilize the extra heat to raise the electrical power supplied to the PFF spacecraft.

All three of these options were investigated in our study.

\section{STIRLING OPTION-1: MODIFIED HEAT SOURCE MODULE}

The modified heat source module for the first of the Stirling options is depicted in Figure 4. It contains six standard 62.5-watt fuel capsules $\left({ }^{238} \mathrm{PuO}_{2}\right.$ fuel and Ir-alloy clads), identical to those used in the safety-qualified GPHS modules. To provide protection in case of inadvertent reentry of the heat source module, the sin fuel capsules are contained in an FWPF (tine-wave-pierced fabric) graphite body, the same material used for the aeroshell and impact shell of the GPHS modules. Its various wall thicknesses exceed the combined thickness of the aeroshell and impact shell in the GPHS.

The space between the fuel capsules and the FWPF body contains pyrolytic graphite (PG) shells. Such shells have been successfully fabricated in the past. Like the very-low-density CBCF (carbonbonded carbon fiber) insulators in the GPHS design, they serve as thermal insulators, to prevent excessive clad temperatures during the reentry heat pulse and to avoid excessive cooling and loss of ductility of the inidium-alloy clads during the subsonic atmospheric descent of the heat source module before earth impact. Impact analyses conducted by Fairchild using the PISCES code indicate that the PG insulators backed up by FWPF offer the clads better impact protection than the $\mathrm{CBCF}$-insulated standard GPHS design. In addition, the modified heat source module has a significantly lower ballistic coefficient and impact velocity ( 33 versus $49 \mathrm{~m} / \mathrm{s}$ ) than the standard GPHS module. For these reasons, the modified design is expected to satisfy or exceed safety requirements, but some confirmatory safety analyses and/or tests would be necessary to demonstrate this.

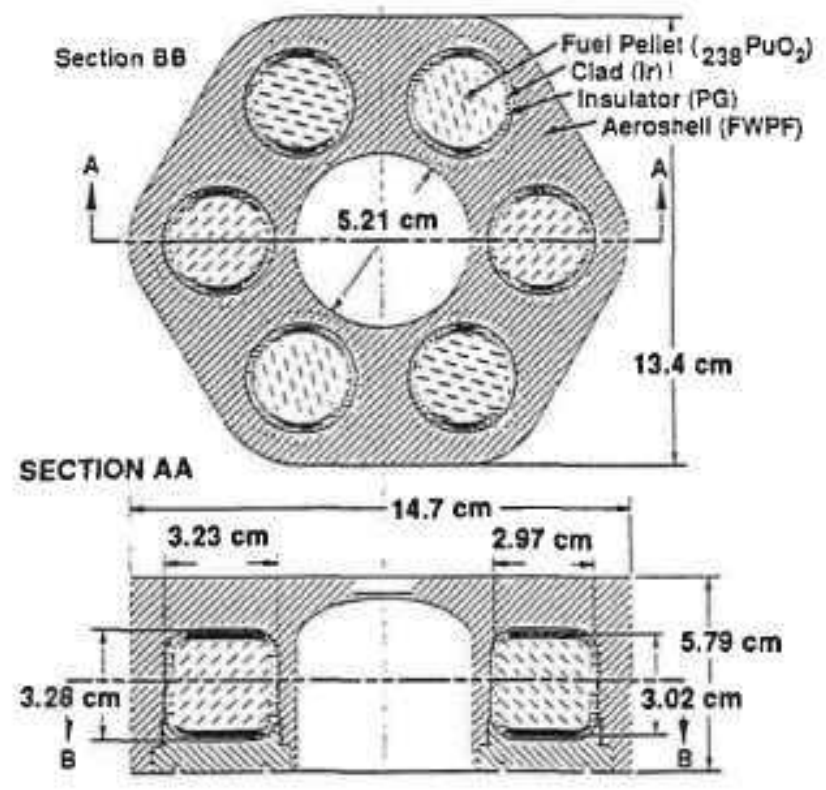

Fig. 4. 375-Watt Heat Source Module Design for Integration with 75-Watt Stirling Engine. (2.53 kg)

The FWPF aeroshell of the modified heat source module has a central cavity designed to facilitate structural integration with the Stirling engine's heater head. This integration scheme is illustrated in Figure 5. As shown, a threaded stud has been added at the axis of the engine's Udimet heater head. This is used to fasten the heat source module to the engine, by means of a graphite nut.

The heat source and the engine's heater head and regenerator are surrounded with multifoil thermal insulation, consisting of 60 layers of $0.00075 \mathrm{~cm}$ thick molybdenum foils separated by zirconia powder particles. The insulated assembly is contained in a housing made of aluminum, beryllium, or magnesium alloy. Aluminum is easiest 


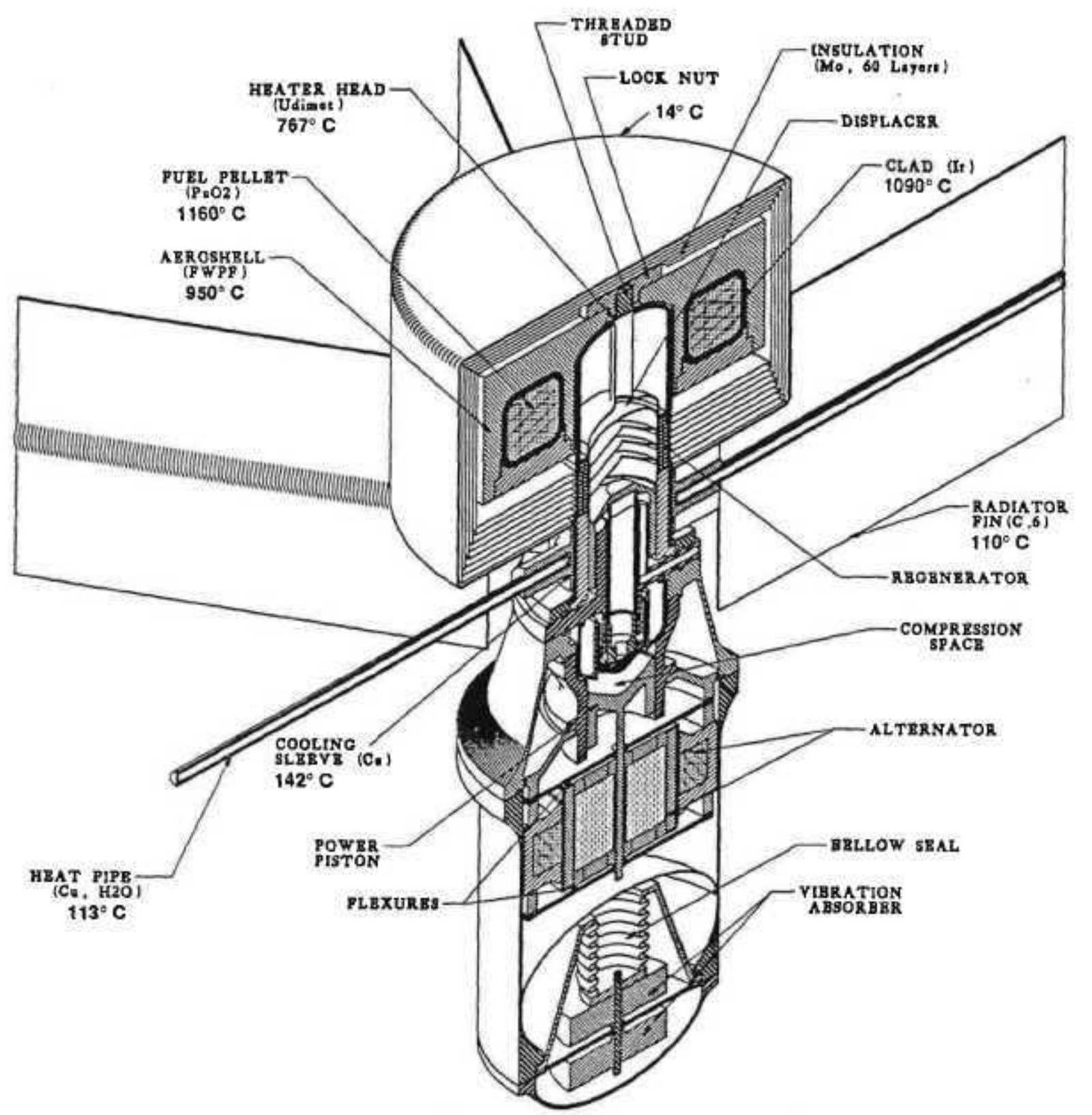

Fig. 5. Stirling System Option 1, Mass $7.3 \mathrm{~kg}$.

to fabricate, but beryllium or magnesium would be significantly lighter. The insulated housing must be vented before arrival at Pluto, but may - if desired be filled with an inert cover gas during launch and cruise.

Figure 5 also shows the radiator used to cool the Stirling engine's heat rejection section. As shown more clcarly in Figure 6 , the cooling assembly consists of six equispaced finned heat pipes. The heat pipes are made of copper and use water as their working fluid. Their condenser sections are brazed to fins made of a recently developed carbon-carbon material having almost twice the thermal conductivity of copper at about one fourth its density. The evaporator segment of the six heat pipes are brazed into finned copper sleeves that are integral parts of a large-diameter copper sleeve brazed to the engine's cooling section.

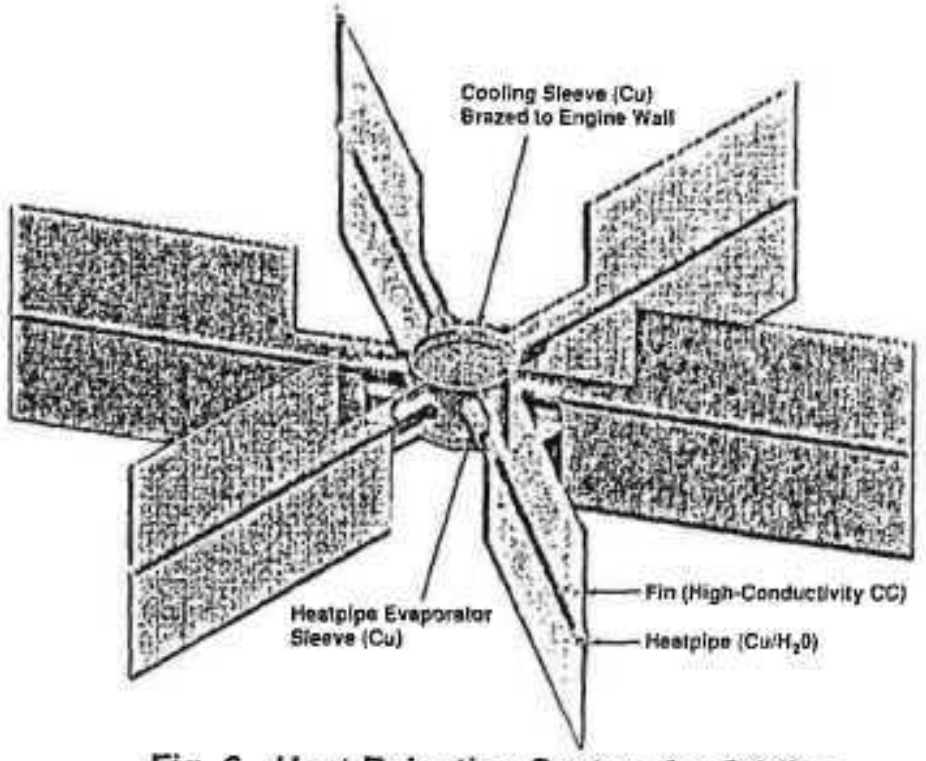

Fig. 6. Heat Rejection System for Stirling Engine Options 1 and 2. 
In performing the thermal analysis of the Stirling System Option-1, a major uncertainty was the contact conductance between the heat source's aeroshell and the engine's heater head. To resolve the effect of that uncertainty, parametric analyses were performed. Figure 7 shows the effect of varying that contact resistance on the normal operating temperatures of the various heat source components. As can be seen, even with zero contact conductance, that is with nothing but radiative heat transfer, the critical iridium clad temperature is less than $1100^{\circ} \mathrm{C}$. This is far below the $1330^{\circ} \mathrm{C}$ temperature limit established to prevent embrittlement of the iridium.

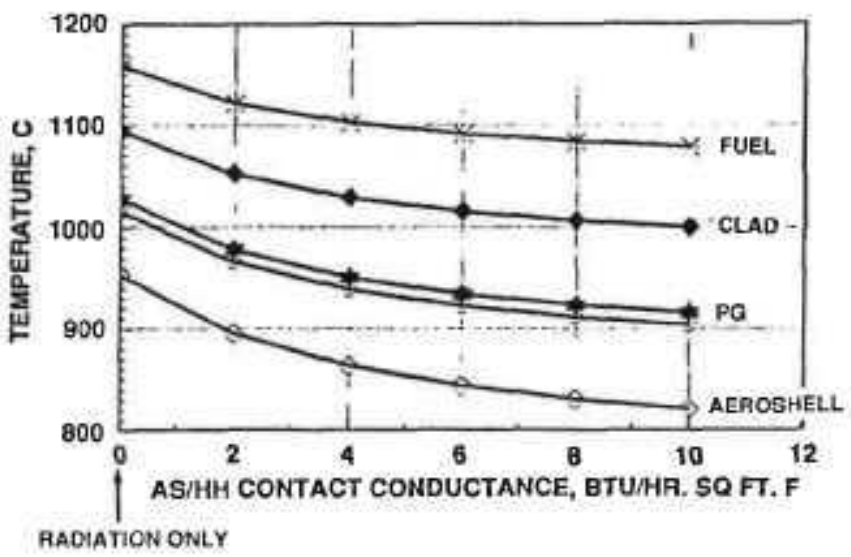

Fig. 7. Effect of Contact Conductance between Aeroshell and Engine's Heater Head on Heat Source Temperatures in Stirling Option 1.

Finally, thermal conduction and radiation analyses were performed to determine the effect of the numbet of finned heat pipes, their (root-to-tip) fin length, and the wall thickness of their evaporator sleeves on the engine's heat rejection temperature, The results of those analyses are displayed in Figure 8. Somewhat surprisingly, it was found that six cooling fins are appreciably more effective than eight, because of better view factors to space. It was also found that the engine heat rejection temperature is quite sensitive to the wall thickness of the copper sleeves into which the heat pipe evaporators are brazed. As can be seen, the engine cooler wall temperature goal can be met with six $20-\mathrm{cm}$ fins and a $0.38 \mathrm{~cm}$-thick evaporator sleeve. The resultant temperature distribution in the integrated heat source, engine, and radiators for this configuration was shown in Figure 5.

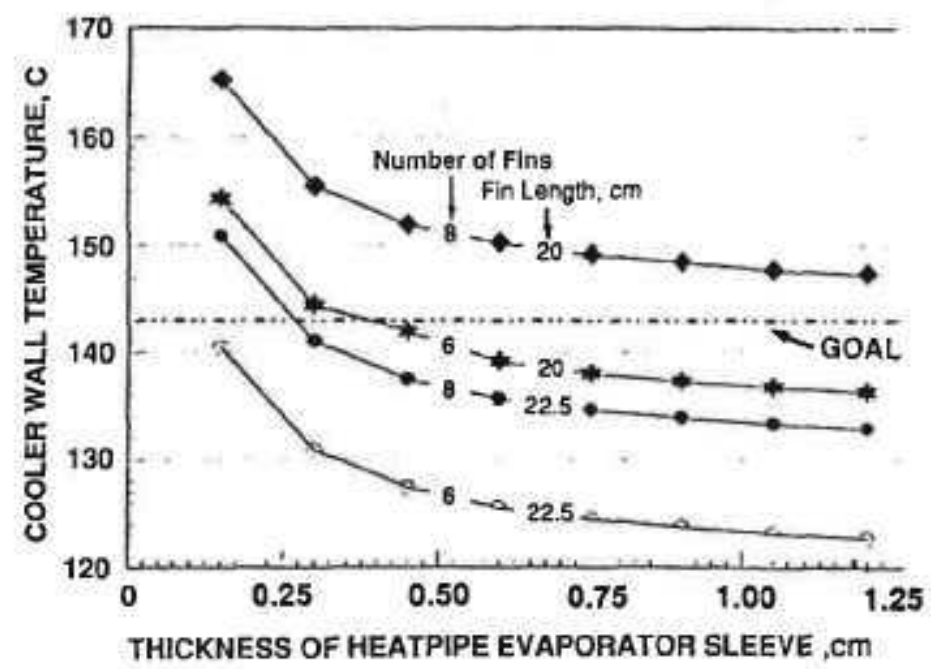

Fig. 8. Effect of Number and Length of Radiator Fins and of Thickness of Heatpipe Evaporator Sleeve on EngIne's Cooler Wall Temperature, Stirling Option 1 and 2.

The Stirling Option-1 design has an overall length of $37.6 \mathrm{~cm}$ and radiator span of $46.2 \mathrm{~cm}$, and a total mass of $7.30 \mathrm{~kg}$. This is also much lower than the lightest of the five RTG options $(10.2 \mathrm{~kg})$, and is even appreciably better than JPL's mass goal of $9.50 \mathrm{~kg}$ for the PFF power source and However, Stirling Option-1 has two major drawbacks: it uses a modified heat source module requiring additional safety verification; and it is a non-redundant system subject to single-point failure. As shown in the Option-2 and -3 designs described below, either or both of these drawbacks can be eliminated, but only at the price of increased mass.

\section{STIRLING OPTION-2: MODIFIED HEATER HEAD}

The Option-2 design is also non-redundant, but it uses two standard GPHS modules instead of the single modified module employed in Option-1. Instead of modifying the heat source, Option-2 employed a Fairchild modification of MTI's heater head design. As illustrated in Figure 9, the engine's heater head has been changed from the cylindrical configuration shown in Figure 2 to a reentrant pancake configuration. None of the other engine or alternator components are changed. The pancake 


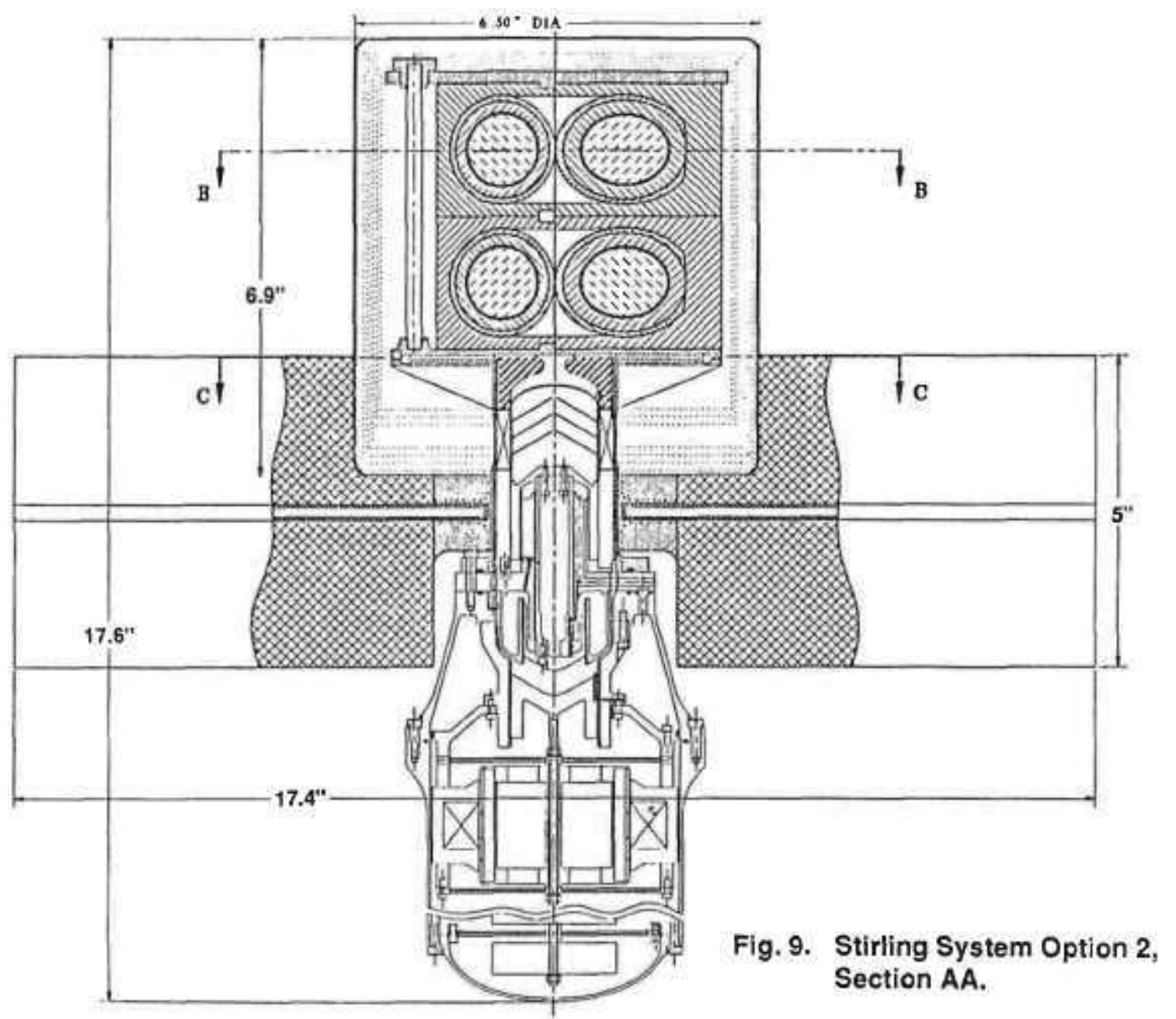

heater head consists of three Udimet disks bonded to each other through radial ribs forming two sets of radial flow passages. During the displacer's upstroke, the engine's helium working fluid flows outward through the upper set of radial passages, turns around at the pancake's edge, and returns through the lower set towards the regenerator.

The two GPHS modules are held against the pancake heater head by means of four tie bolts, as illustrated in Figure 10. The four bolts are tied to a graphite hold-down plate, as shown in Figure 9. As in Option-1, the heat source and regenerator are surrounded by multifoil thermal insulation and an outer housing. The upper heat source module runs somewhat hotter than the lower, but thermal analysis showed that its clad temperatures were well within the prescribed limits.

Figure 10 also shows the six radiator fins which serve as the engine's heat rejection system, similar to the Option-1 design. The Option-2 Stirling system has an overall height of $44.7 \mathrm{~cm}$ and radiator span of

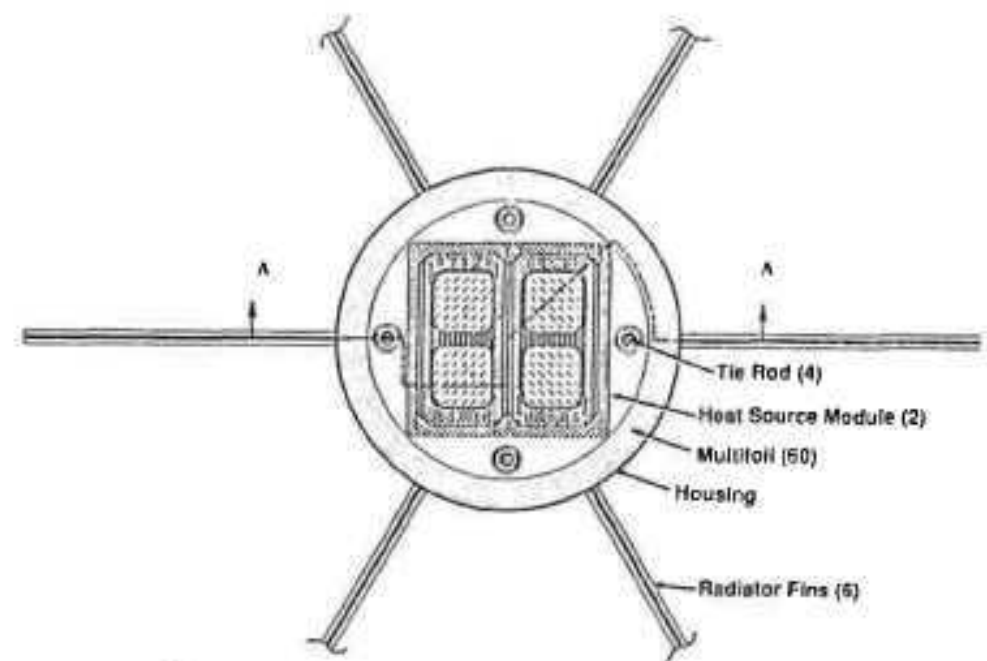

Fig. 10. Stirling System Option 2, Section BB Heat Source.

$44.2 \mathrm{~cm}$, and a total mass of $8.77 \mathrm{~kg}$ compared to $7.30 \mathrm{~kg}$ for the Option-1 design. The difference of $1.47 \mathrm{~kg}$ is the price for avoiding the need for a modified heat source module. 
The MTI engine and alternator can produce 75 $w(e)$ with a heat input of $326 w(t)$. But the two GPHS modules used in Option-2 can accommodate up to $500 \mathrm{w}(\mathrm{t})$. This presents the mission designer with three suboptions:

2a. Reduce the fuel loading and/or enrichment to lower the thermal power from 250 to $163 \mathrm{w}(\mathrm{t})$ per heat source module.

2b. Fully fuel the GPHS modules to produce 500 $w(t)$, and increase the engine's stroke length to raise its electrical output. According to MTI, this could yield an output to $110 \mathrm{w}(\mathrm{e})$.

2c. Fuel the two GPHS modules to their full 500watt thermal power, and keep the electrical output at 75 watts by substituting a less efficient but lighter engine. According to MTI, this could reduce the engine mass by $0.50 \mathrm{~kg}$. Thus, this suboption would lower the system efficiency from $20 \%$ to $15 \%$, and reduce the power source mass from $8.75 \mathrm{~kg}$ to $8.25 \mathrm{~kg}$.

Of the three suboptions, Suboption-2b may be of particular interest if the $47 \%$ increase in electrical output is of value to the spacecraft and mission designers. For example, such an increase in available power could substantially shorten the postencounter downlink period.

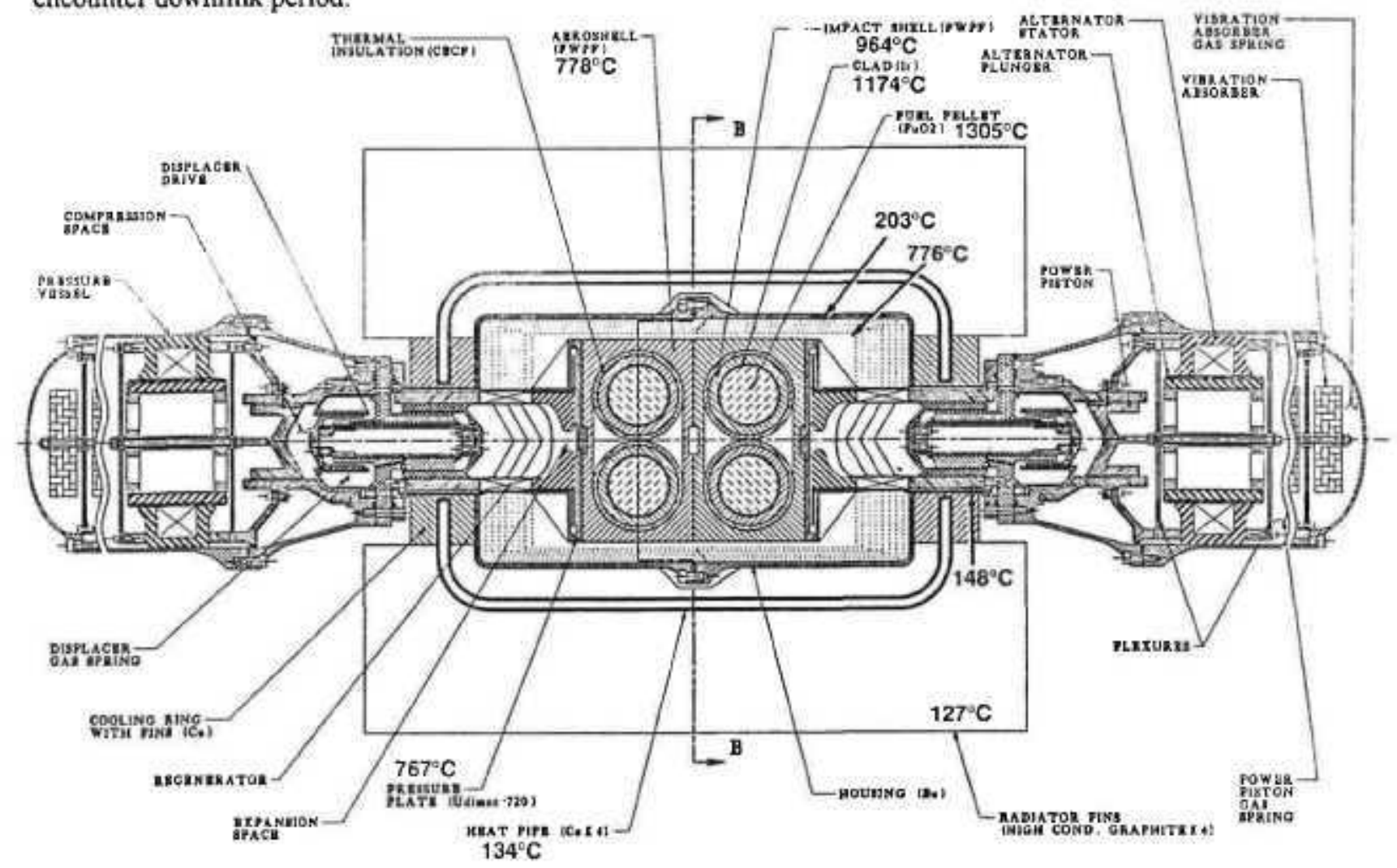

Fig. 11. Stirling System Option 3, Section AA, Normal Operating Temperatures.

\section{STIRLING OPTION-3: REDUNDANT SYSTEM}

Since neither Option-1 nor Option-2 is redundant, failure of the Stirling engine would terminate the mission. The overall system reliability could be greatly enhanced if the power system were provided with redundancy to avoid the risk of single-point failures. A design for a redundant power system is presented in Option-3.

The radioisotope heat source is so reliable, it does not need to be redundant. Its heat-generating reliability is already $100 \%$. Similarly, the multi-fin radiator is already redundant, since failure of one of the heat pipes would only result in a modest temperature rise with negligible effect on power output. Thus, system redundancy can be achieved by having a system with two Stirling engines (and alternators), each able to deliver the full design power if the other failed. To do so in a masseffective manner, Fairchild generated a system design that integrated two Stirling engines with a common heat source and radiator.

As shown in Figure 11 the Stirling System Option-3 design employs two 75-watt MTI engines with their heater heads modified as in Option-2. The radioisotope heat source consists of two standard 
GPHS modules. These are supported by the pancake-shaped heater heads of the two engines. As shown, the assembly is held together at the midplane of the heat source housing by means of a bolted flange joint sealed by a metal $\mathrm{C}$-ring. The heat rejection system of the two engines consist of four finned heat pipes at $90^{\circ}$ intervals. As shown in Figure 11, each heat pipe is U-shaped, with its two ends brazed to the cooling sleeves for the two engines. Thus, each fin serves to cool both engines.

Under normal operating conditions, with both engines operating, each heat source module supplies heat to one engine, and each engine operates at reduced stroke to produce half the design power. Each end of each heat pipe acts as an evaporator to help cool its engine, and the heat pipe's middle section acts as a common condenser (with bidirectional vapor flow that meets at the center).

If one engine fails, its temperature rises and the heat from both heat source modules flows to the good engine. Then the good engine's control system automatically adjusts its stroke length to produce the full design power at the same temperature and pressure. Each heat pipe has only one active evaporator which receives the heat rejected by the operating engine. Unidirectional vapor flow through the heat pipes' condensers distributes the reject heat over the full length of the radiator fins, so that the operating engine's heat rejection temperature is essentially unchanged.
The heat rejection temperature with either one or both engines operating is a function of the root-to-tip fin length and the thickness of the copper sleeves into which the heat pipe evaporators are brazed. Figure 12 shows the results of thermal conduction and radiation analyses. As can be seen, the desired cooler wall temperature can be achieved with a fin length of less than $10.2 \mathrm{~cm}$ giving a radiator span of $27.9 \mathrm{~cm}$.

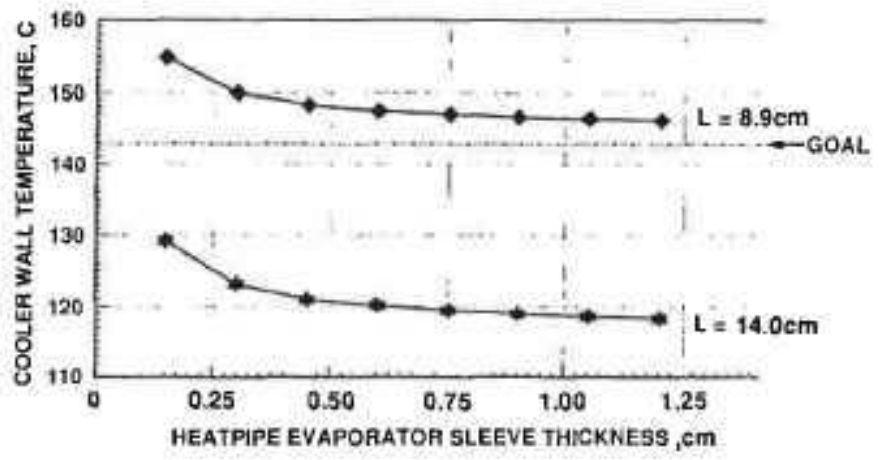

Fig. 12. Effect of Radiator Fin Length and Thickness of Heatpipe Evaporator Sleeve on Engines' Cooler Wall Temperature.

The resultant system temperatures are shown in Figure 11 for the normal-operation case and in Figure 13 for the case in which the left engine has failed. In that case, the left heat source module is running significantly hotter than the right, since the heat generated by the former must pass through the latter to reach the good engine. But as shown, the clad temperature in the hotter module is still only $1252^{\circ} \mathrm{C}$, well below the prescribed $1330^{\circ} \mathrm{C}$ limit.

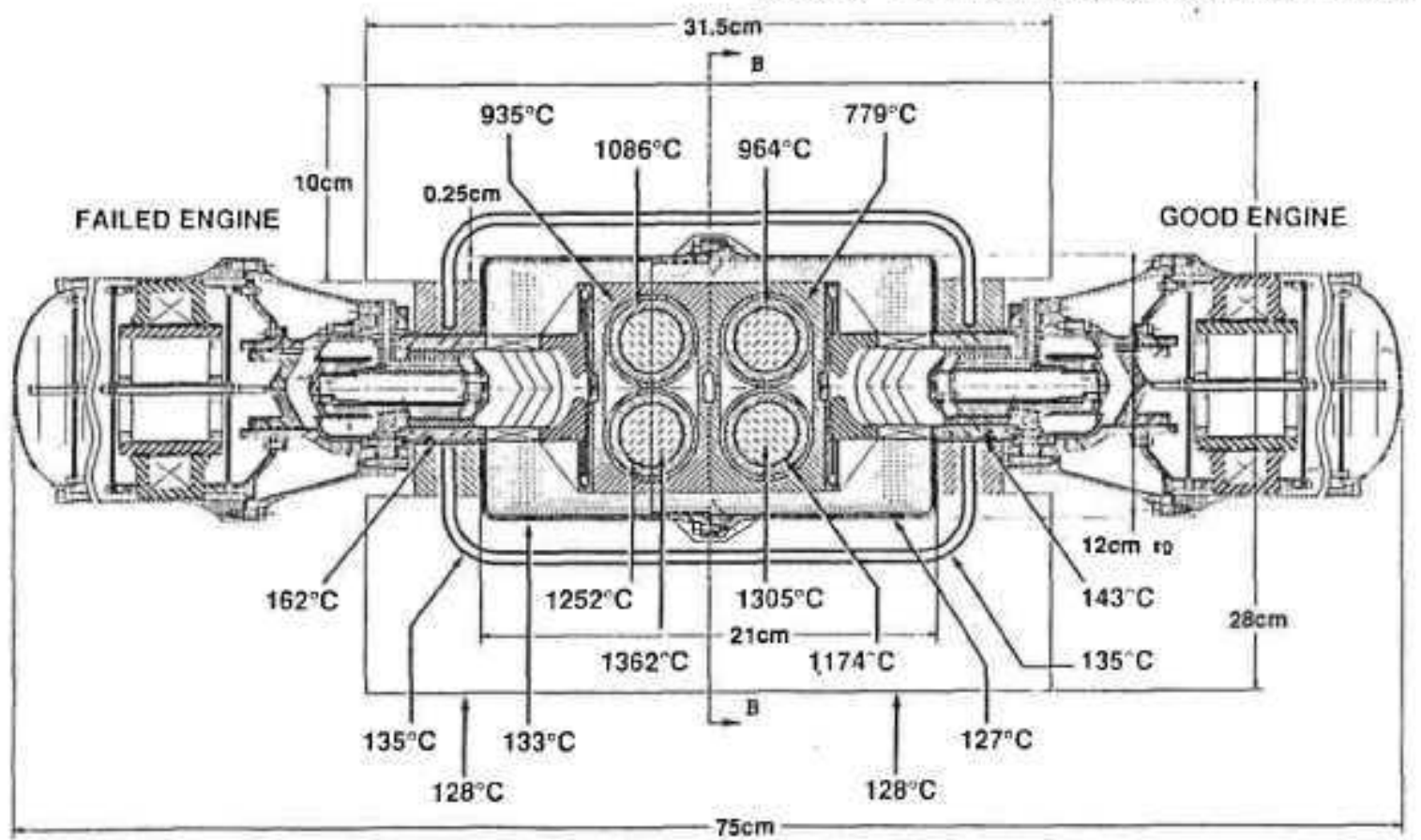

Fig. 13. Stirling Option 3 Temperature with One Engine Falled, All Temperatures are within Acceptable Limits. 
The Option-3 Stirling System has an overall length of $31.5 \mathrm{~cm}$ and a total mass of $11.31 \mathrm{~kg}$ compared to $8.77 \mathrm{~kg}$ for Option-2. The $2.54-\mathrm{kg}$ mass increase is the price for achieving redundancy and eliminating the risk of single-point failures. It should be noted that the three suboptions described for Option-2 are also available for Option-3. If desired, Option-3 could generate up to 110 watts(e), with redundancy

\section{CONCLUSIONS}

The purpose of the detailed DOE-sponsored system design studies conducted by Fairchild was to help clarify the available radioisotope power system options for the Pluto Fast Flyby mission, and to provide reliable mass estimates and technology status assessments.
Detailed designs for eight radioisotope power system options ( 5 thermoelectric and 3 Stirling) were prepared and analyzed. Their respective masses are summarized in Table 2. As can be seen, the options requiring least development and having least programmatic risk are the heaviest, and the lighter options are generally more risky or require more development.

The study results are designed to support informed trade-off decisions by program management. Even if it were decided that the more advanced technology options are incompatible with the specific PFF launch schedule, they do offer great multi-mission benefits in mass and cost reduction and should therefore be pursued by DOE and NASA for future space missions requiring small radioisotope power systems.

Table 2. Computed System Masses of Radioisotope Power Source Options Included in Fairchild Studies.

Thermoelectric:

Unicouples:

$19.3 \mathrm{~kg}$ Option 1: Scaled-down GPHS/RTG ( 5 instead of 18 heat source modules)

$15.4 \mathrm{~kg}$ Option 2: Modified heat source support structure

Multicouples:

$13.4 \mathrm{~kg}$ Option 1: Modified MOD/RTG design

$12.2 \mathrm{~kg}$ Option 2: Square instead of cylindrical housing

$10.2 \mathrm{~kg}$ Option 3: Same with multiple-voltage output, no DC-to-DC converters

\section{Stirling Engine:}

$7.3 \mathrm{~kg}$ Option 1: MTI engine. Modified heat source module (1)

$8.8 \mathrm{~kg}$ Option 2: Modified MTl engine. Standard heat source modules (2)

$11.3 \mathrm{~kg}$ Option 3: Redundant system. Two MTI engines with common heat source and radiaiot

\section{Acknowledgments}

The author takes pleasure in acknowledging the vital role played by MTI personnel (G. Dochat, N. Vitale, M. Dhar) in designing and analyzing the Stirling engine and alternator, their LeRC sponsor (J. Dudenhoefer), and the Fairchild personnel who prepared the design drawings (K. Sankarankandath) and performed the thermal analysis (T. Or, H. Noravian) of the integrated system. The Fairchild study was supported by the Department of Energy's Office of Special Applications (R. Lange, Director).

\section{$\underline{\text { References }}$}

Dochat, G. and J. Dudenhoefer (1994) "Performance Results of Stirling Power Converter," CONF9450101 for presentation at the 11th Symposium on Space Nuclear Power, to be held in Albuquerque, NM in January 1994.
Dochat, G.R. and J.E. Dudenhoefer, (1993) "Stirling Technology Development Status," in Proc. of the 10th Symposium on Space Nuclear Power Systems, CONF-930103, M.S. El-Genk and M.D. Hoover, eds, American Institute of Physics, New York, AIP Conference Proc. No 271, 2: 1039 - 1044.

Schock, A. (1980) "Design Evolution and Verification of the General-Purpose Heat Source," \#809203 in Proc. of 15th Intersociety Energy Conversion Engineering Conference, held in Seattle, WA.

Schock, A. (1994) "Radioisotope Thermoelectric Generator Options for Pluto Fast Flyby Mission," CONF-9450101 for presentation at the 11th Symposium on Space Nuclear Power, Albuquerque, NM. 